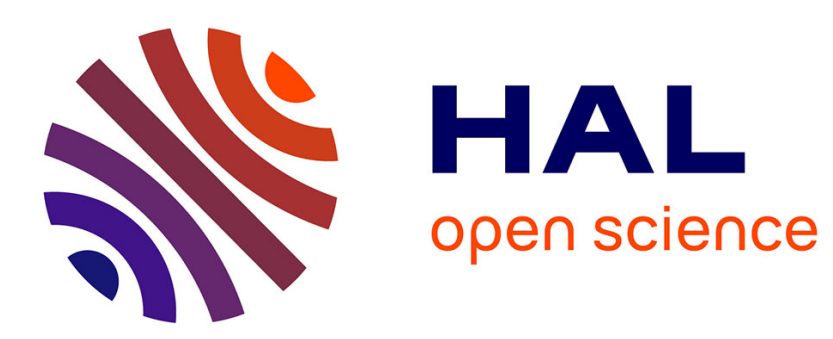

\title{
Prediction of the machining defects in flank milling
}

Arnaud Larue, Bernard Anselmetti

\section{To cite this version:}

Arnaud Larue, Bernard Anselmetti. Prediction of the machining defects in flank milling. International Journal of Advanced Manufacturing Technology, 2004, Vol. 24/1-2 (1), pp. 102-111. 10.1007/s00170003-1774-z . hal-00098361

\section{HAL Id: hal-00098361 \\ https://hal.science/hal-00098361}

Submitted on 16 Feb 2018

HAL is a multi-disciplinary open access archive for the deposit and dissemination of scientific research documents, whether they are published or not. The documents may come from teaching and research institutions in France or abroad, or from public or private research centers.
L'archive ouverte pluridisciplinaire HAL, est destinée au dépôt et à la diffusion de documents scientifiques de niveau recherche, publiés ou non, émanant des établissements d'enseignement et de recherche français ou étrangers, des laboratoires publics ou privés. 


\title{
A prediction of the machining defects in flank milling
}

\author{
A. Larue, B. Anselmetti
}

\begin{abstract}
In peripheral milling with great axial engagements, the tool deflections generate some geometrical defects on the machined surface. This article present a prediction method of these defects which is applicable on every ruled surface. The cutting forces are estimate with the cutting pressure notion. The parameters of the tool/workpiece material couple are identified by a test part. The prediction of the tool deflections requires controlling the tool immersion angle for each angular position of the tool. The deflections can be significant. An original procedure which is based on an engagement cards avoids an iterative calculation of the radial engagement. The experimental checking of the method of prediction is presented in a test.
\end{abstract}

Keywords Peripheral milling - Tool deflections . Identification of a tool workpiece material couple . Engagement cards

\section{Introduction}

\subsection{Presentation}

The present study is about flank milling using the long cutters of free forms. This free forms are made up of ruled surfaces. This very powerful process, from a productivity and surface quality point of view, is very popular in aeronautics and mould manufacturing.

The magnitude of the defect induced by the deflection of a long HSS cutter with a diameter of $20 \mathrm{~mm}$ can reach $0.7 \mathrm{~mm}$ for a radial engagement of $3 \mathrm{~mm}$. Such geo-

\footnotetext{
A. Larue $(\bowtie)$

LURPA Ecole Normale Supérieure de Cachan,

61 Av Pt Wilson, 94235 Cachan Cedex, France

E-mail: larue@lurpa.ens-cachan.fr

Tel.: + 33-1-47402765

Fax: + 33-1-47402220

B. Anselmetti

Institut Universitaire de Technologie de CACHAN,

9 avenue de la division, Leclerc 94234 Cedex, France
}

metrical variations induce the nonrespective of the part specifications.

The purpose of this article is to establish a prediction method of flank milling defects at low speeds which can be integrated in a computer aided sesign and manufacturing software (CAD/CAM).

The characterisation of the tool deflections is based on a cutting pressure model. The model parameters are gauged by milling a test part on the production machine tool. When the tool workpiece couple is identified, the influence of the tool deflection on the part geometrical defects can be predicted.

\subsection{The problem}

To predict tool deflection, it is necessary to control the engagement of the cutting edges into the workpiece material at every moment.

At high cutting speed, chatter vibration phenomena appears $[1,2]$. To model that phenomena, lots of research took the mass, the damping and the acceleration of the milling structure into account $[3,4,5,6]$. These studies allow the prediction of the vibratory behaviour of the structure. Firstly, they result in long calculations which are difficult to implement in a CAD/CAM system on all the surfaces to machine. Secondly, such studies require a dynamical protocol to identify the dynamical structure characteristics and the force model parameters.

Our objective at low speed milling was to predict the surface defects and to compensate for the tool paths. We also needed a model which was easy to identify and fast to use. We showed that a satisfying result can already be obtained without taking the vibratory behaviour into account [7]. That's why the calculation of surface defects thus passes by the motion study of the generating point of each cutting edges in catch in the workpiece material.

In fact, the surface is generated by the cutter sweeping. Each rule of the surface is obtained by the generating point displacement along the helicoidal cutting edge during the rotation of the cutter. 
The tool deflection can be calculated at every moment using a model resulting from the materials resistance theory (RdM).

The cutting forces applied to the tool thus depend on the number of teeth in catch and on the length of the cutting edge engaged in the workpiece material at every moment.

It is thus necessary to calculate the immersion angles for each cutting edge starting from the finished surface and from the rough surface defined by the CAD model. This calculation must be carried out for each rule and for each angular position of the cutter.

During our tests, we have showed that the deflections are so significant that it is absolutely necessary to take the deflection into account to calculate the cutting edge engagement. In the first approach, this analysis requires considering an iterative calculation process which is very expensive in terms of computation times. The article's purpose is to establish a precise process, which avoids this iterative calculation in the majority of the cases. It presents the engagement card concept which represents the tool load during the milling.

\section{The modelisation of surface defects}

\subsection{The surface generation}

The problem studied is the peripheral milling of a ruled surface. Our interest is focused on the down milling case. At first approximation, the tool path is generated so that during that time, the cutter generatrix is combined with the various rules of the surface. However, the surface concavity is not constant along the rule. Various techniques of the cutter axis shifting make it possible to improve the milling quality by limiting the undercut and the overcut $[8,9,10,11]$.

This work thus considers that the CAM system constructs the tool path generation and gives the tool axis (axis $\vec{z}$ position $A_{n}$ and the normal to the machined surface $\vec{y}$ at every moment, which makes it possible to define the cutting section $S_{n}$ at the curvilinear abscissa $S_{a}{ }^{n}$ along the directrix (Fig. 1). $\vec{x}$ completes the trihedral $\vec{x}, \vec{y}, \vec{z}$ in the feed direction.

In this section, we will suppose that the generatrix to machine is the line $\Delta_{n}$. Our objective is thus to determine the variations of the machined surface position compared with the theoretical line $\Delta_{n}$. These variations are added to the undercut and overcut defects. The different sections will be studied with a "normal" step and a "reduced" step. The reduced step will be used when some engagement discontinuities are detected on the machined surface or on the rough surface.

The generating point of a tool is mobile on the line $\Delta_{n}$. At moment $t$, the generating point is in $P$ at distance $z$ of the tool holder which is supposed to provide a perfect embedding. It is thus necessary to know the tool deflection in $P$ which will be equal to the surface position variation in this point.

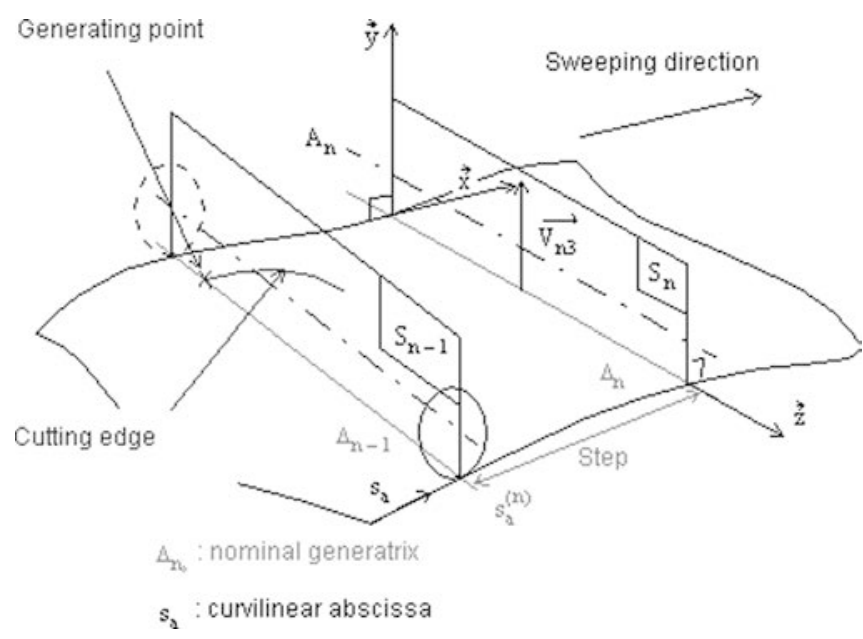

Fig. 1 The place of the generating points

At moment $t+\delta$ t, the generating point is in $P^{\prime}$ at the distance $z$ ' (Fig. 2).

The deflection varies according to the generating point $P$, which generates a deformed profile on the surface.

\subsection{The deflection model}

Our deflection model correspond to an extension of the Kline and DeVor model [12], which has involved lots of semi static models $[13,14,15]$.

At a given moment, the generating point is in $P$. Each elementary length of the cutting edges in catch in the workpiece generates an elementary tool deflection in $P$. The sum of these deflections gives the variation of the surface in $P$.

At point $Q$ located along the cutting edge, the angular position is $\beta$. The force applied in $Q$ on a part of the cutting edge, whose elementary length is $d z$, consists
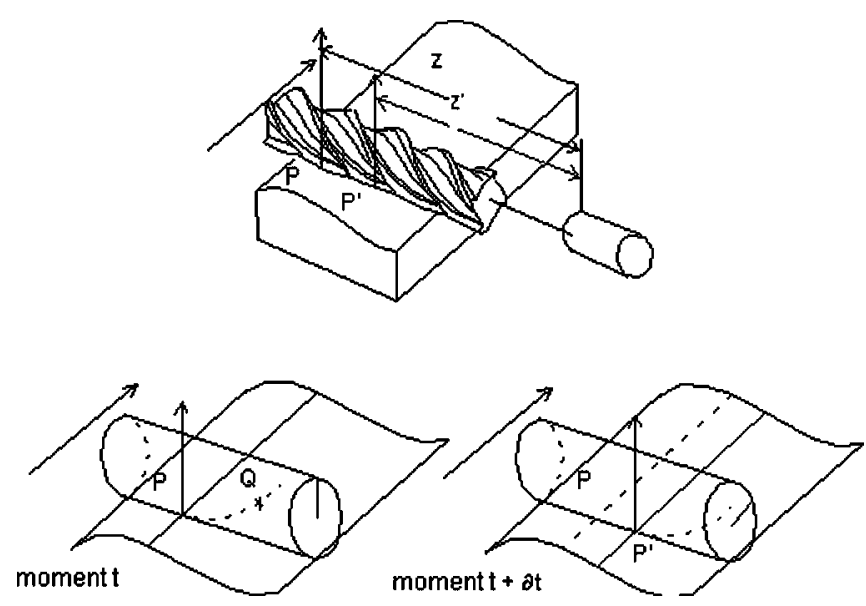

Fig. 2 The evolution of the generating point of a tool 
of a tangential component $d F t$ and a radial component $d F r$.

The cutting forces are obtained with the following model:

$d F r=K r \cdot e p \cdot d z=K r_{0} \cdot f z \cdot \sin (\beta) \cdot d z /(f z \cdot \sin (\beta))^{0.3}$

$e p$ is the depth of cut given by: $e p=f z \cdot \sin (\beta)$.

$f z$ is the feedrate per tooth.

$K r=K r_{0} \cdot e p^{-0.3}$ and $K t=K t_{0} \cdot e p^{-0.3}$

The cutting pressures $K r_{0}$ and $K t_{0}$ are characteristics of the tool workpiece material couple. They are determined by an identification test.

Only the normal component $d N$ of the cutting force acts on the machined surface deformation (Fig. 3):

$d N(\beta)=d F r(\beta) \cdot \cos (\beta)+d F t(\beta) \cdot \sin (\beta)$

In $P$, the resulting deflection $d y$ induced by the force $d N$ applied to point $Q$ is given by a simple model of a fixed beam of the constant quadratic moment of inertia: $I_{G y}$ (Fig. 3).

$$
\begin{aligned}
d y= & \frac{1}{E \cdot I_{G y}} \cdot d N(\beta) \\
& \left.\cdot\left[\left(\frac{(z-L(\beta))^{3}}{3}\right)+\frac{(z-L(\beta))^{2} \cdot L(\beta)}{2}\right)\right]
\end{aligned}
$$

where $L(\beta)=(h \times \beta / 2 \pi)$ is the distance between $P$ and $Q$ for the tooth which leaves its trace on the part, $h$ being the helicoidal milling cutter step.

A similar relation is defined for the points $Q$ which belong to the following cutting edge in catch (when $Q$ is on the left of $P$ ).

For each point $P$, the theoretical total deflection is the sum of the elementary deflections generated by all the points $Q$ of the cutting edges simultaneously engaged in the workpiece material.

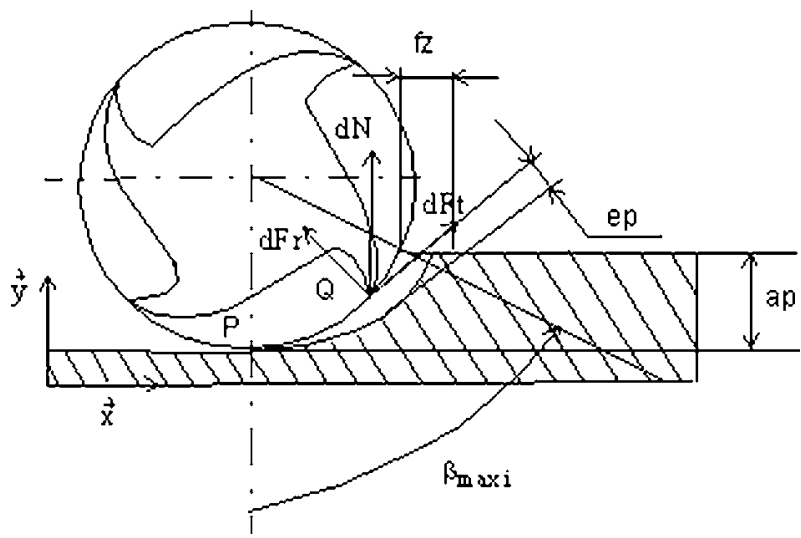

Fig. 3 The deflection model definition $y t h=\sum_{k=1}^{N c}\left(\int_{\beta_{\min }}^{\beta_{\operatorname{maxi}}} d y_{k}\right)$

where $N c$ is the number of cutting edges in catch.

The difficulty of the calculation lies in the definition of the maximal and minimal immersion tool angles $\left(\beta_{\text {maxi }}\right.$ and $\left.\beta_{\text {mini }}\right)$. These angles are defined by the intersection of the screw which characterises the tool cutting edge when the generating point is in $P$. $\beta_{\operatorname{maxi}}$ corresponds to the intersection with the rough surface. $\beta_{\text {mini }}$ corresponds either to the intersection with the finished surface $\left(\beta_{\operatorname{mini}}=0\right)$, or to the intersection with the side of the part $\left(0 \leqslant \beta_{\text {mini }} \leqslant \beta_{\text {maxi }}\right)$. This calculation will be developed in paragraph 4 , because it should take the tool deflection into account. Figure 4 shows the calculation of the resulting deflection $d y$ at point $P$.

\subsection{The identification of the coefficients}

To determine the coefficients $K r_{0}$ and $K t_{0}$, an identification protocol on an unspecified industrial milling machine was proposed [7, 16, 17]. The identification procedure consists in the down peripheral milling of a plan starting from the test part defined in Fig. 5. The width of the part is slightly higher than $\frac{h}{Z}$ where $h$ is the tool helicoïdal pitch and $Z$ is the total number of teeth. The radial depth of cut varies gradually from 0.5 to $3 \mathrm{~mm}$ (Fig. 5). The tool end is left free so as to make it possible to study only the influence of the helicoidal cutting edge on the part defect.

From an operational point of view, the identification procedure consists in milling the test part and measuring the defects of the machined surface.

The immersion angles can be calculated by taking the tool deflection which is estimated starting from the measured dots into account.

The coefficients $K r_{0}$ and $K t_{0}$ are calculated by minimising the sum of the squares of the differences between the dots measured and the dots simulated.

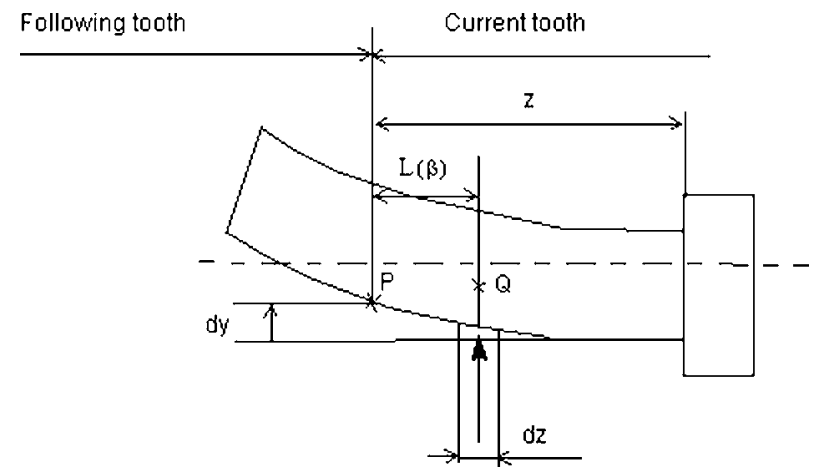

Fig. 4 The calculation of the resulting deflection dy at point $P$ 


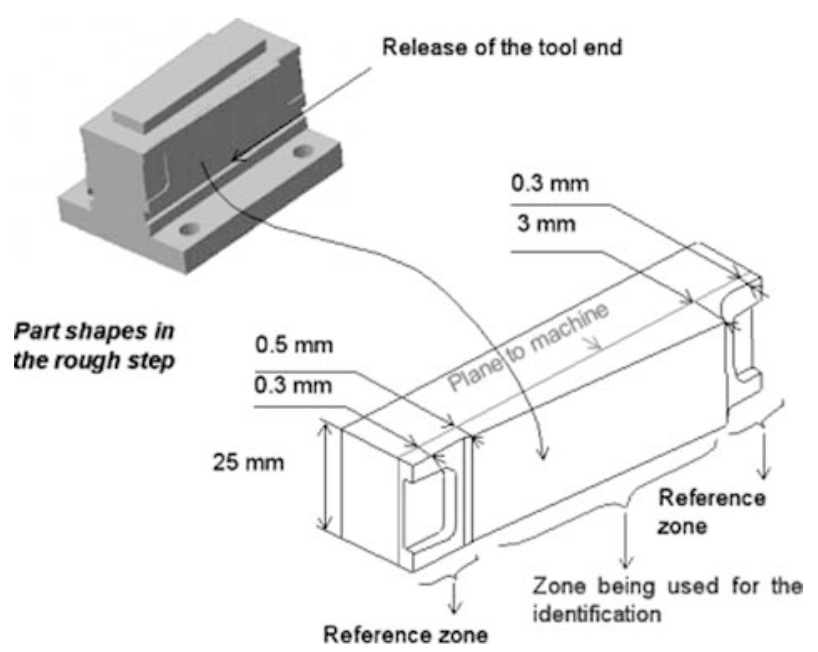

Fig. 5 The part for the calibration of the tool workpiece material couple

2.4 The identification of the tool workpiece material couple

For our application, the conditions of the identification test are the following:

HSS tool of diameter $20 \mathrm{~mm}$, whose active length is $88 \mathrm{~mm}-4$ teeth:

- Machined workpiece material: C48

- Milling on a vertical milling centre

- $V c=25 \mathrm{~m} / \mathrm{min}$

$-f_{z}=0.2 \mathrm{~mm} /$ tooth

With $I_{G y}=7,854 \mathrm{~mm}^{4}$, the coefficients calculated are:

$K r_{0}=312$

$K t_{0}=120$

The simulated machine surface is illustrated in Fig. 6.

Several tests showed that these coefficients are almost independent from the cutting speed.

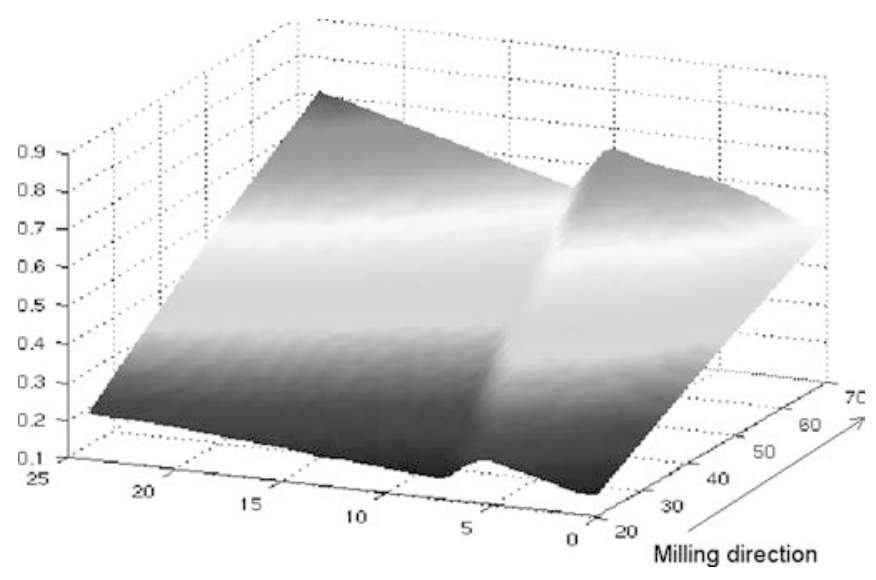

Fig. 6 A simulation of the machined surface

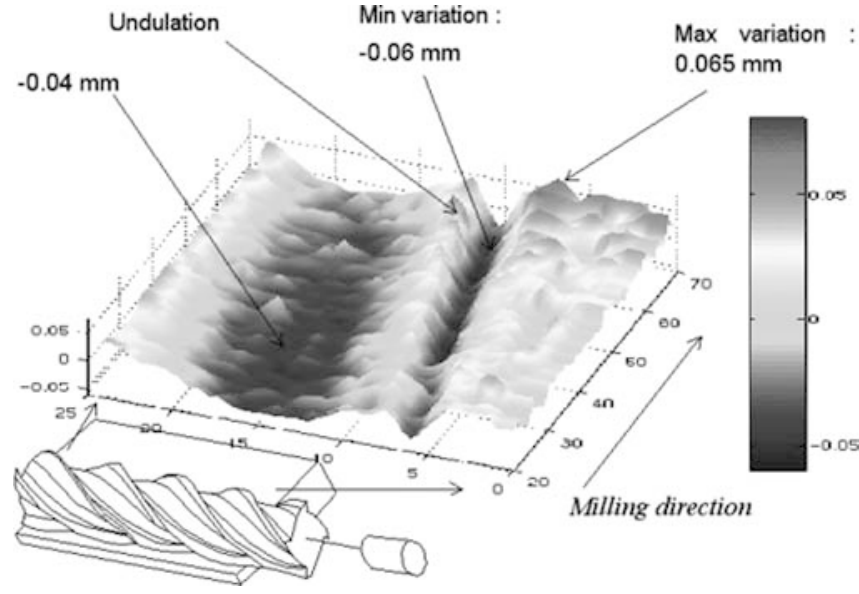

Fig. 7 A comparison of the simulated and machined surfaces

Figure 7 shows that the difference between the simulated and the cloud of theoretical dots lie for 95 percent of the surface between $\pm 0.05 \mathrm{~mm}$.

\section{The prediction of the milling defects in CAM}

\subsection{Introduction}

The work objective is to predict the form and the position variations of the flank machined surfaces. These variations are due to the tool deflections generated by the variable cutting forces. The part deformations and the machine deformations are not taken into account. These cutting forces are depending on the cutter immersion angle at every moment which also considerably depends on the tool deflection, which makes the calculation difficult (Fig. 8).

In front of this problem, we propose a defects prediction method which is applicable in a CAD environment for the milling of an unspecified ruled surface. The final geometry to obtain is thus defined by a CAD model. The tool paths are initially given by the CAD for example with the use of tool laying techniques on a surface, suggested by Rubio [8], Tönshoff [9] and Affouard [10].

By misnomer, we call the "rough" surface of the part the part surface before the tool passes. This raw part can be described by a CAD model or by a raw management dynamical system according to the tool paths during the preceding operations (NCSIMUL software [18], Vericut software [19] and Delmia software [20]). In all cases, the radial engagement is supposed to be lower than the cutter diameter: $a p \leq 2 \times R$, in order to exclude the milling in full matter.

\subsection{The prediction algorithm in steady mode}

An iterative solution would firstly consist in calculating the cutter deflection by considering the theoretical angle 
Fig. 8 An influence of the tool deflection on its maximum immersion angle

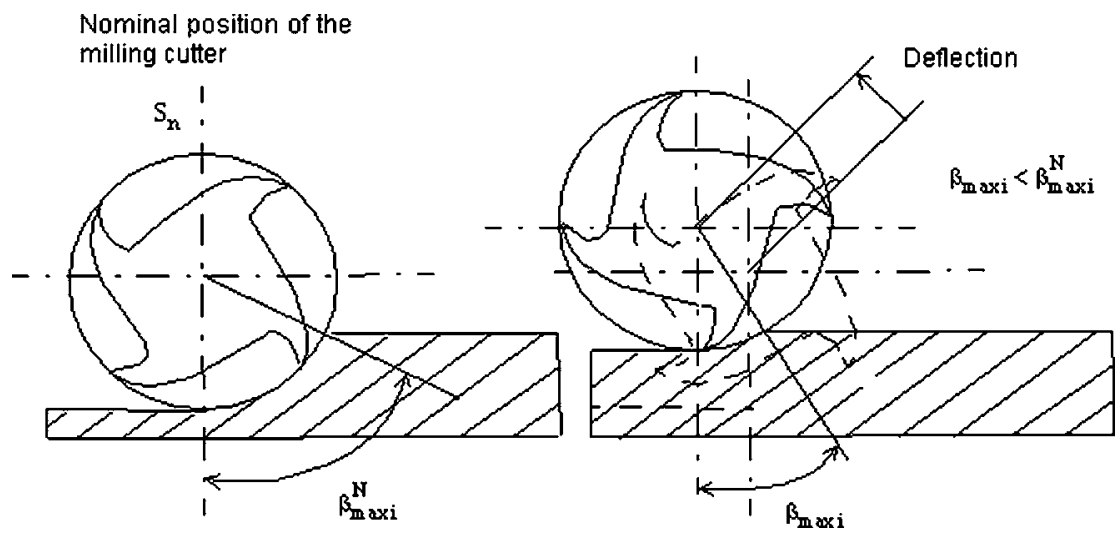

of immersion obtained with a perfectly rigid cutter; in the following iterations, the angle depends on the presumed deflection at the preceding stage. The iteration alternates geometrical "RdM" calculations and geometrical calculations. It stops when the deflection converges. Calculations with this method are very long and not quite acceptable in the CAD universe [21, 22, 23, 24].

We propose a solution without iteration by estimating that the profile $E_{n}$ named estimated profile in the section $S_{n}$ will be similar to the calculated profile $C_{n-1}$ in the preceding section $S_{n-1}$ (Fig. 1 and Fig. 9). This assimilation makes it possible to calculate the immersion angle directly.
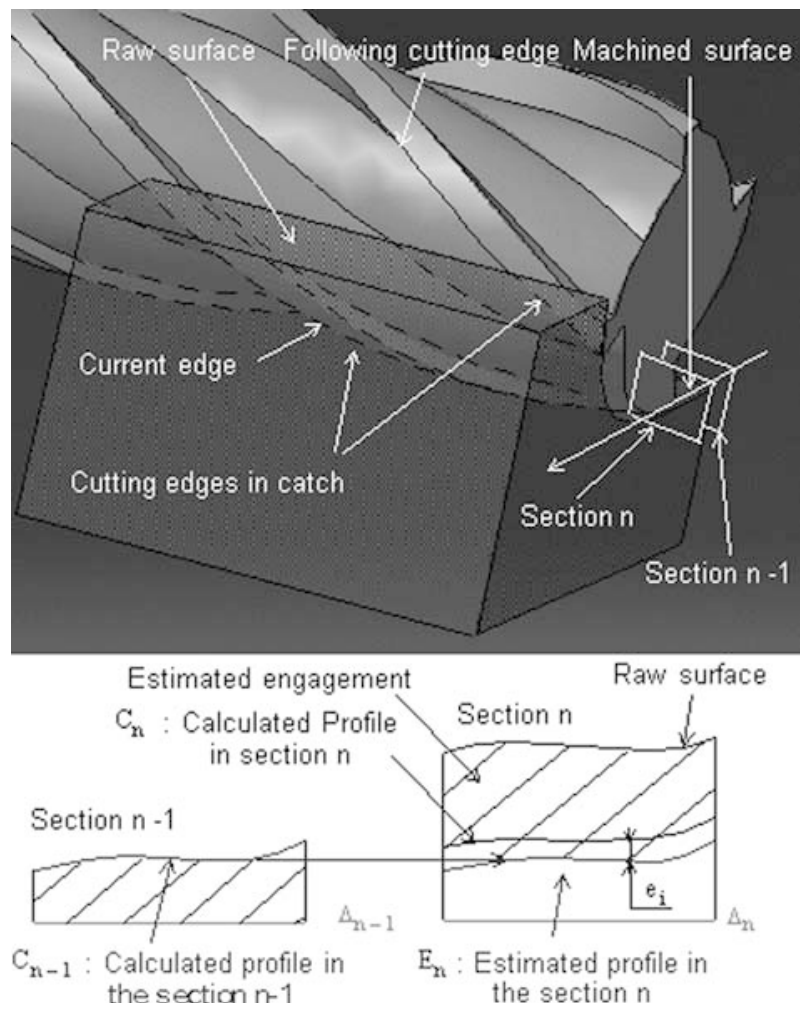

Fig. 9 An initialisation of the tool estimated position in a given section in steady state
This supposes that the tool deflection at section $n-1$ is near the deflection at section $n$. This assumption is plausible when the machined surface and the rough surface are continuous, which is often the case. An iterative process will be however necessary in the case of discontinuities (see paragraph 3.3). Once the deflection is initialised, the algorithm calculates the immersion angles and determines the profile calculated of section $n$. Figure 10 presents the principles of the calculation process.

The preceding algorithm is valid in a steady state.

It must be completed to treat two other cases.

Case 1: The tool crosses a transition zone (the zone where the engagement conditions rapidly vary).

Case 2: The tool enters the workpiece material (the initialisation of the calculation).

\subsection{The crossing of a transition zone}

When the raw surface geometry is discontinuous between two sections of calculation (the presence of a step, the presence of a hole, etc.), the deflection variation can

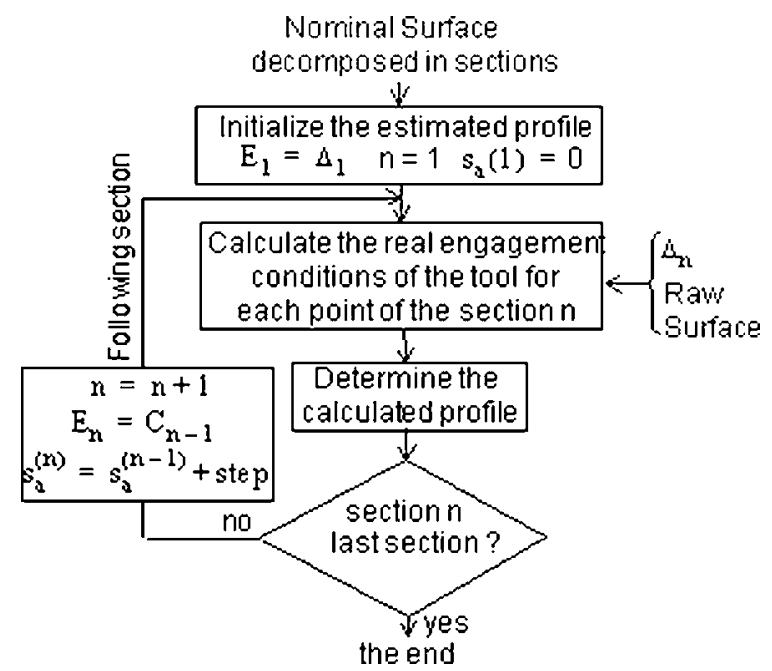

Fig. 10 The basic algorithm in the steady state 
be very significant. A solution consists in increasing the number of sections to make the engagement variation progressive. We hence adopt a reduced step. The reduced step is equal to the normal step divided by ten.

The process seen in a steady state can thus be used again simply by decreasing the step between the sections. Such a discontinuity is detected simply when the difference between the presumed profile and the calculated profile is too significant. The following criterion was used:

$$
\frac{1}{N} \times \sum_{i=1}^{N}\left(y t h_{i C}-y t h_{i E}\right)^{2} \leqslant L^{2}
$$

$N$ is the number of dots treated on the profile. $L$ is a limit translating the acceptable average distance.

$y t h_{i C}$ is the calculated deflection at point $\mathrm{i}$ on the calculated profile.

$y t h_{i E}$ is the calculated deflection at point $\mathrm{i}$ on the estimated profile.

- When this criterion is not respected, the step is reduced.

- When this criterion is not respected with a reduced step, the iterative calculation is necessary by taking the profile $C_{n-1}$ calculated at the preceding stage as the estimated profile $E_{n}$. The iteration continues as relation 5 is completed.

- If relation 5 is respected directly without iteration on ten sections, we go back to the normal step. Figure 11 shows the thickening of the number of sections at the time of a transition zone passage

\subsection{The tool input in the workpiece material}

The first section considered is a section which is out of the workpiece material (Fig. 12).

For the first section, the estimated profile $E_{1}=\Delta_{1}$.

Generally, in this first section, the tool is out of the workpiece material and there is no deformation. Criterion 5 is thus checked before passing to the following step. If the tool is directly in the workpiece material, it is necessary to pass to the iterative process, seen in the case of a strong engagement discontinuity.

\subsection{Complete algorithm}

All the processes that we have just exposed can be summarised in only one prediction algorithm (Fig. 13).

It should be noted that this calculation is carried out in the CAD universe for geometrical calculations then in the numerical universe of "RdM" calculations (with Matlab software).

To carry out this change of work universe, the values $\beta_{\text {mini }}$ and $\beta_{\text {maxi }}$ calculated in CAD are memorised under the shape of an engagement line $L(n)$ (see paragraph 4).

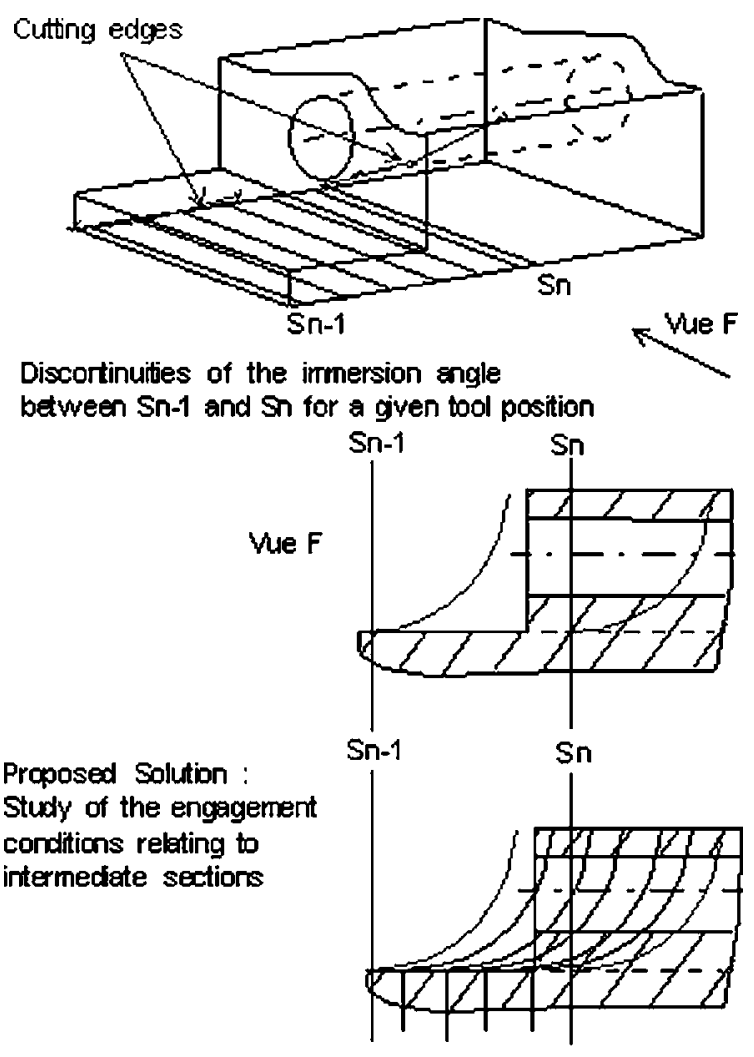

Fig. 11 The thickening of the number of sections at the time of a transition zone passage

\section{The calculation of the workpiece engagement}

4.1 The conditions of calculation of real tool engagement

A cutting edge is engaged into the workpiece material between an angle $\beta_{\text {mini }}$ and an angle $\beta_{\text {maxi }}$. Generally, $\beta_{\text {mini }}=0$ if point $P$ is on the surface. On the other hand, on the edges of the part, the following cutting edge cannot be completely engaged, in this case $\beta_{\text {mini }}>0$ (Fig. 9).

The limits $\beta_{\operatorname{mini}}$ and $\beta_{\operatorname{maxi}}$ must thus be calculated starting from the intersection of the screw representing the tool cutting edge with the rough surface and the faces of the part. It is hence necessary to define the tool position and the tool inclination for all points $P$ of the estimated profile with precision.

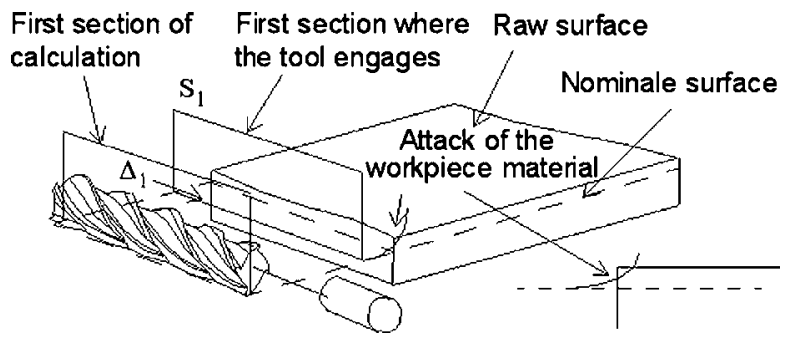

Fig. 12 The definition of the first calculation section 


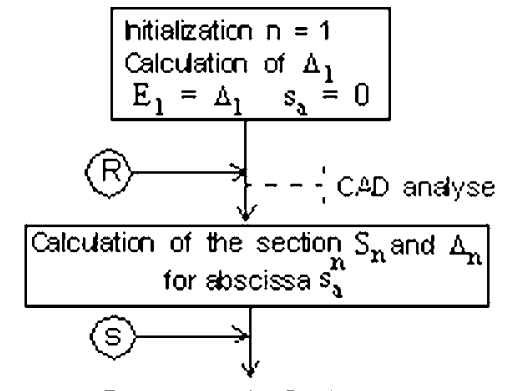

For each poirt $P$ of $\Delta_{n}$

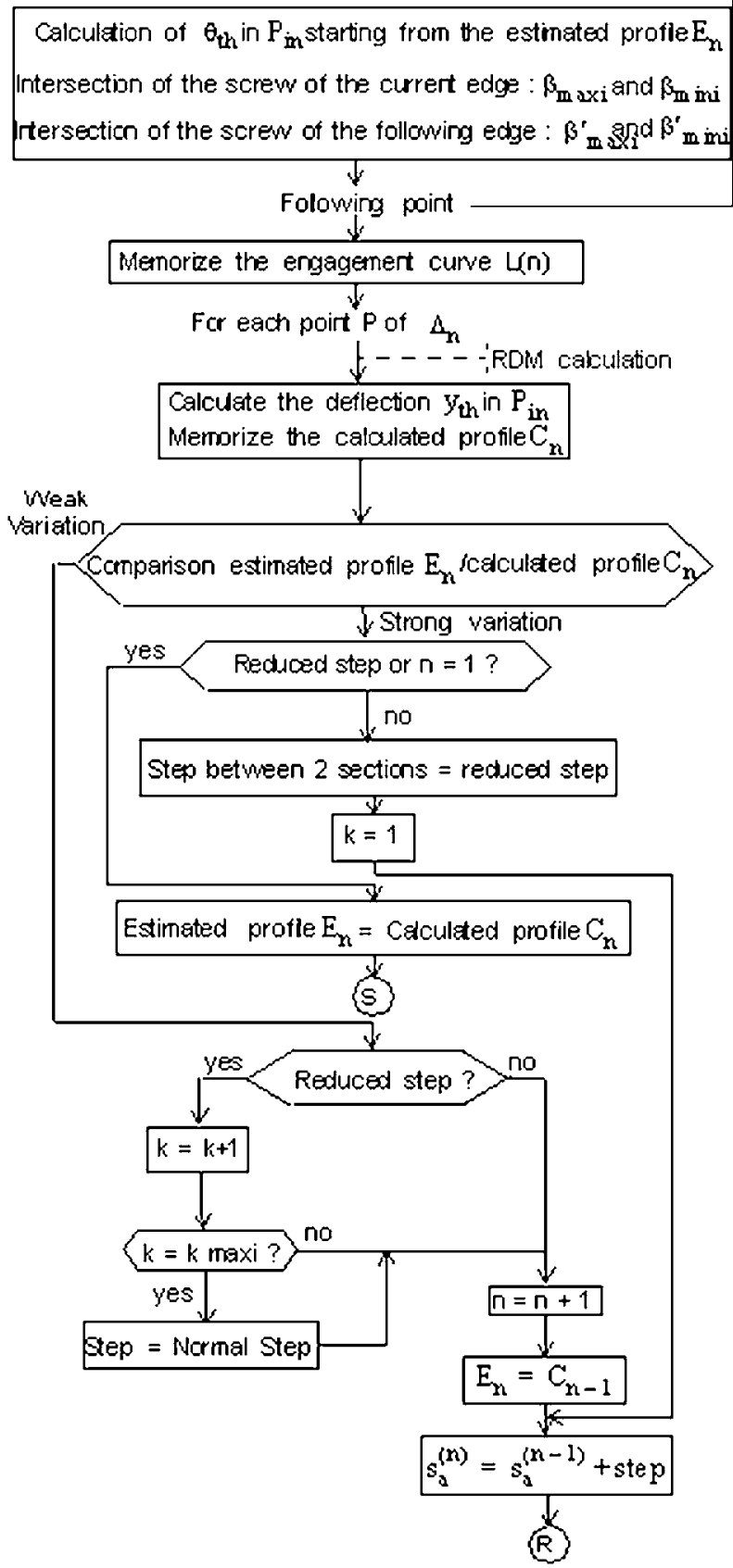

Fig. 13 The complete prediction algorithm

If the milling cutter were perfectly rigid, the generatrix would be the line $\Delta_{n}$. When we have only one generating point $P$, we consider that the tool generatrix follows a curve of degree 2, tangent to the line $\Delta_{n}$, tangent to the tool embedding in the tool holder and passing by the point $P$.

If there are two points $P 1$ and $P 2$ pertaining to two successive cutting edges simultaneously, it is considered that the tool generatrix follows a curve of degree 3 passing by these two points and tangent to the embedding.

For each point of the estimated profile $E_{n}$, we build a local reference mark $P, \vec{x}_{P}, \vec{y}_{P}, \vec{z}_{P}$ where $\vec{x}_{P}$ is the unit vector indicating the milling direction, $\vec{z}_{P}$ is the tangent unit vector to the curve and $\vec{y}_{P}$ the vector defined such as $\vec{y}_{P}=\vec{z}_{P} \wedge \vec{x}_{P}$. In this reference mark, the cutting edge is defined by a parametric equation:

$$
\begin{aligned}
& x=r \times(\sin (2 \pi \times t / h)) \\
& y=r \times(1-\cos (2 \pi \times t / h)) \\
& z=t
\end{aligned}
$$

In the reference mark $P, \vec{x}, \vec{y}, \vec{z}$, the helical cutting edge is defined with:

$$
\begin{aligned}
& x=r \times(\sin (2 \pi \times t / h)) \\
& z=r \times \cos \left(\theta_{P}\right) \times(1-\cos (2 \pi \times t / h))-t \times \sin \left(\theta_{P}\right) \\
& z=r \times \sin \left(\theta_{P}\right) \times(1-\cos (2 \pi \times t / h))+t \times \cos \left(\theta_{P}\right)
\end{aligned}
$$

The intersection of the screw with the rough surface is done by searching $t_{\text {maxi }}$, which gives $\beta_{\text {maxi }}=2 \pi \mathrm{t}_{\text {maxi }} / h$. When point $P$ is on the finished surface, $\beta_{\text {mini }}=0$. On the other hand, the following cutting edge starts in a point $P$ located out of the workpiece material. The intersection of the cutting edge with the edge of the part makes it possible to determine $\beta_{\text {mini }}$. We thus obtain the integral terminals allowing to calculate the machined surface defects (Eq. 4). Figures 14, 15 and 16 show the tool deflection model, a local reference mark of the milling cutter and the definition of an engagement line.

Orly one generating point $P$

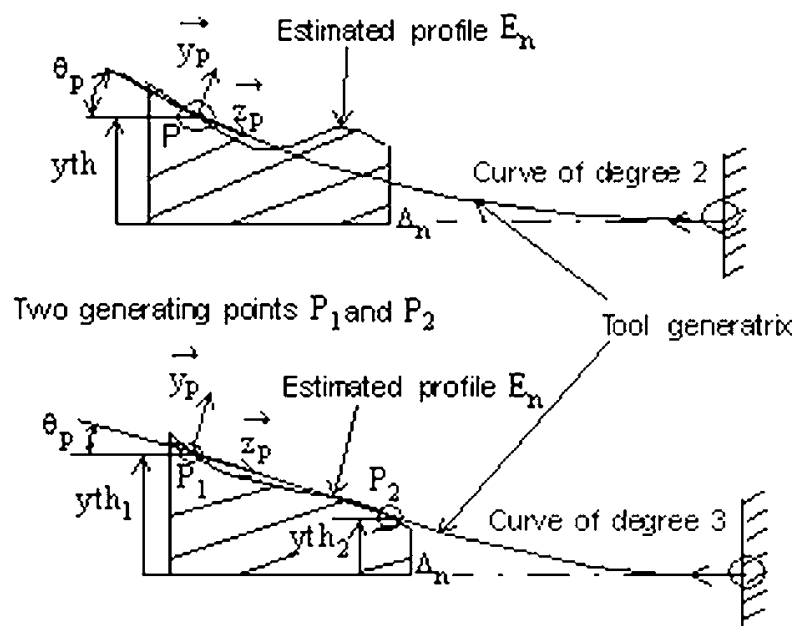

Fig. 14 The tool deflection model: approximation by a polynomial curve 


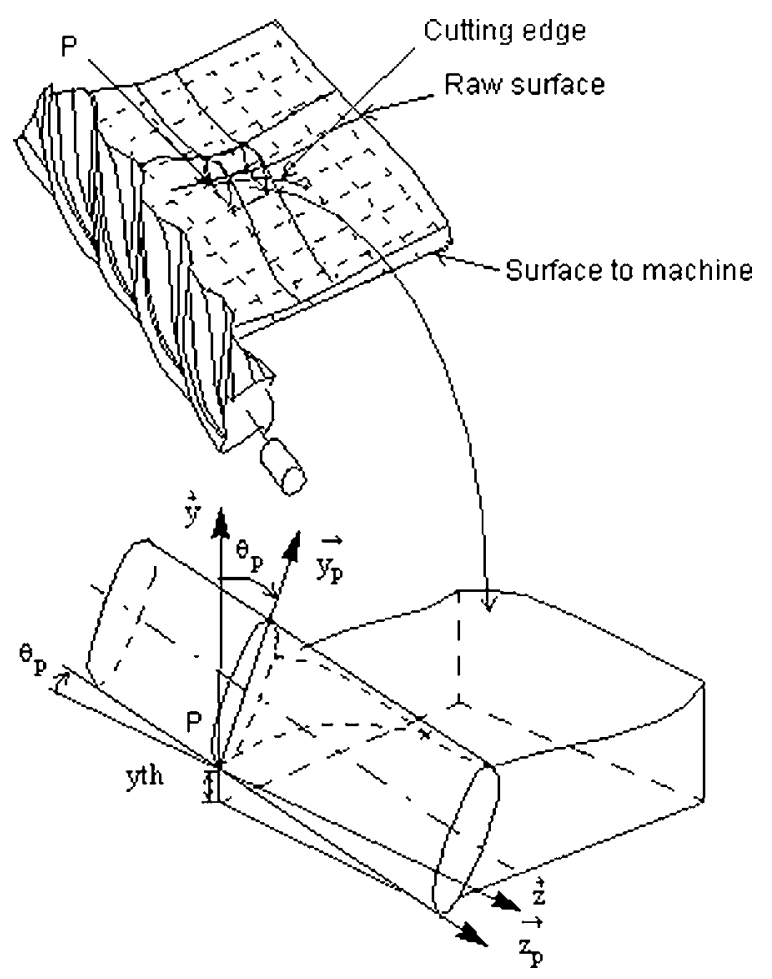

Fig. 15 The local reference mark of the milling cutter

4.2 The definition of the workpiece material engagement card

During the study of a section, for each point $P$, the calculations made it possible to calculate the angles $\beta_{\text {mini }}$ and $\beta_{\text {maxi }}$ of the cutting edge. These values can be recapitulated on two engagement curves.

This curve is perfectly defined for all the points $P$ located between the edges of the part. This curve is prolonged on the left when the point $P$ is located out of the workpiece material and that the cutting edge is engaged

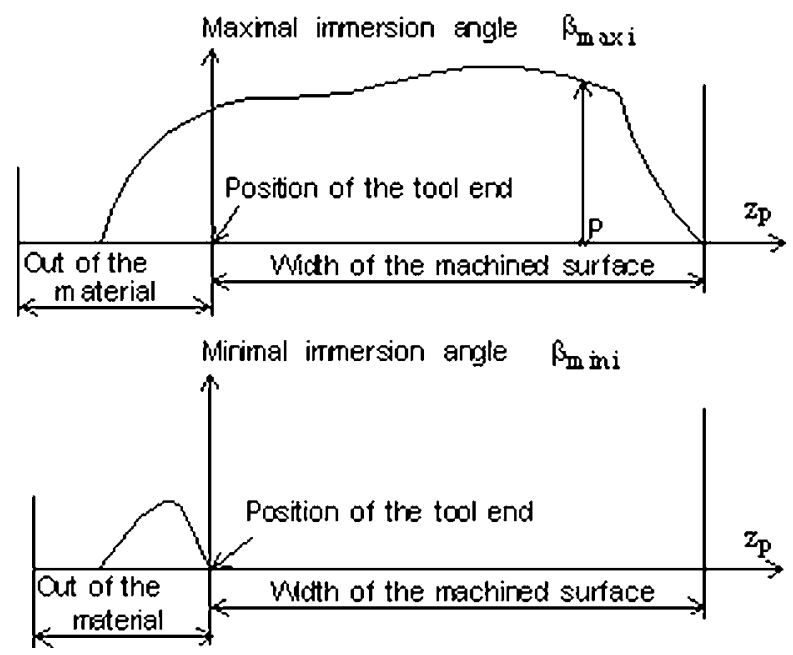

Fig. 16 The definition of an engagement line in the workpiece material with angles $\beta_{\operatorname{mini}}$ and $\beta_{\operatorname{maxi}}$. For the points between the edges of the part $\beta_{\text {mini }}=0$, except if the rough surface comprises holes.

The juxtaposition of the maximum engagement lines defines the maximal engagement card. The minimal engagement card is defined in a similar way. These cards give a global and continuous vision of the engagement workpiece material during the milling. This makes it possible to rapidly identify the zones presenting some milling difficulties and those for which the engagement is significant.

\section{An application of the prediction method}

\subsection{The milling process description}

This defect prediction method is applied to the case of the milling of a cylindric part by circular interpolation. The tool radial depth of cut during the milling is equal to $2 \mathrm{~mm}$ (Fig. 17).

\subsection{The calculated profile}

In the steady mode (between 2 and 3), we obtain the calculated profile of the machined surface: we can represent the machined surface variation in function of the curvilinear abscissa.

\subsection{The engagement line}

On this application, only two teeth to the maximum engage simultaneously. The maximum engagement card is described according to the curvilinear abscissa. Three phases are thus distinguished as follows: the input in the workpiece material (1), the steady state (Fig. 18) (2) and

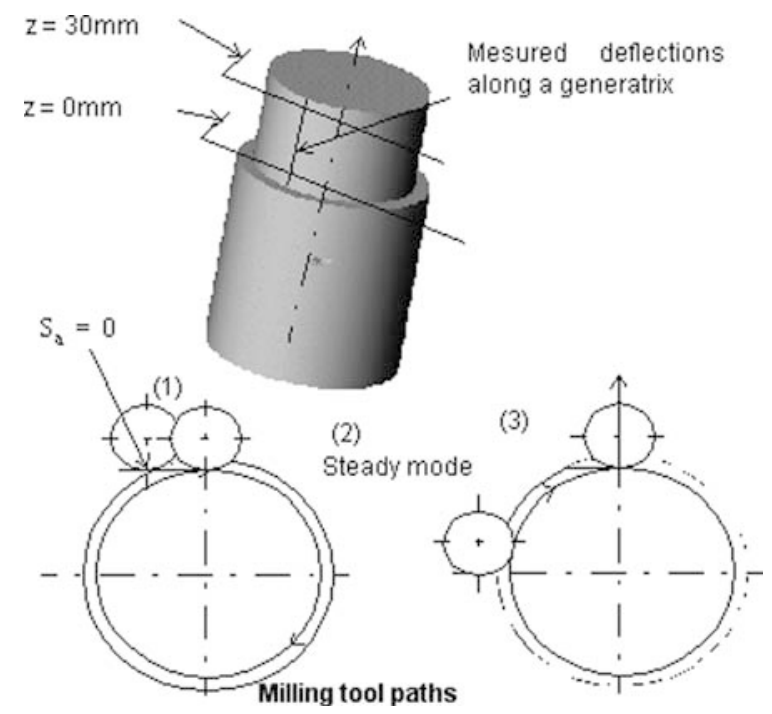

Fig. 17 The validation of the identification protocol 


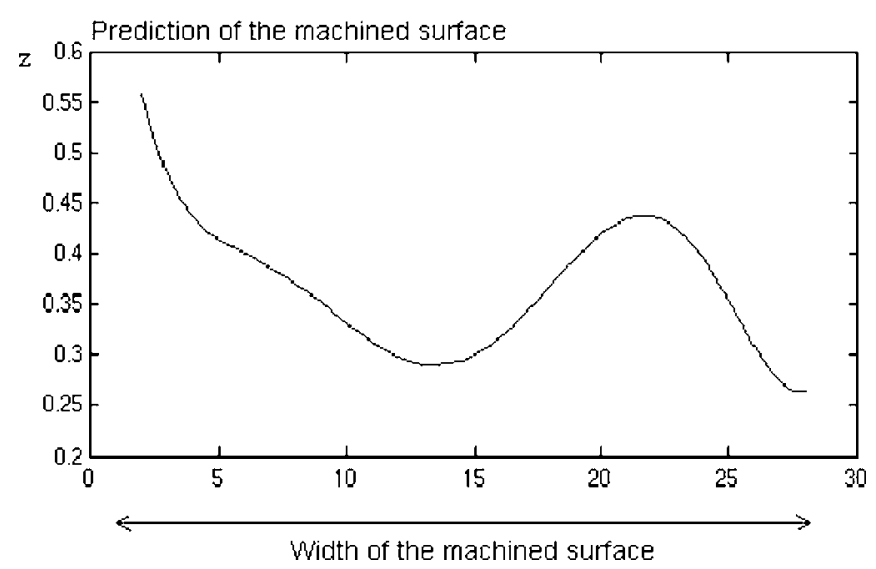

Fig. 18 The calculated profile in the steady mode

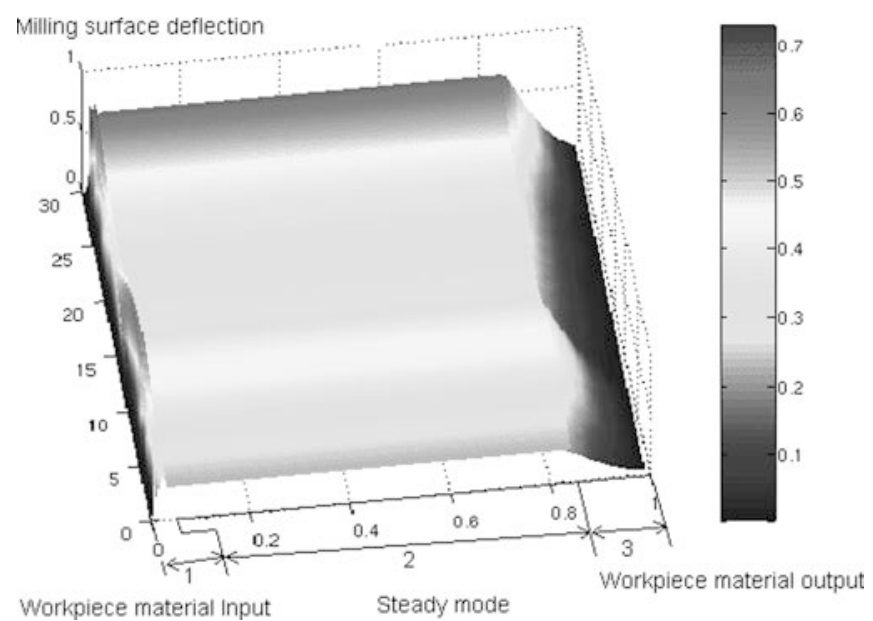

Fig. 19 The simulation of deflection of the machined surface

the output of the workpiece material (3). (Fig. 19 shows a simulation of deflection of the machined surface.

The raw part is analysed in function of the curvilinear abscissa, because it changes during the time. That is the case in particular with the tool return in zone number 3.

The maximum engagement card (Fig. 20) shows that on a section extracted from the steady mode phase the maximum immersion angle clearly increases then decreases when the generating point moves away from the embedding position. We see that the more significant the deformation is, the less the tool engages in the workpiece material as was described in paragraph 4.2.

\subsection{Verification}

The real defect of the machined surface is measured on several generatrix. When the tool is in a steady state (except for the input in the material and the output from the material), the real deflection is compared with the simulated deflection (Fig. 21).

The global error between the predicted form and the form which really is machined is lower than $0.05 \mathrm{~mm}$ on

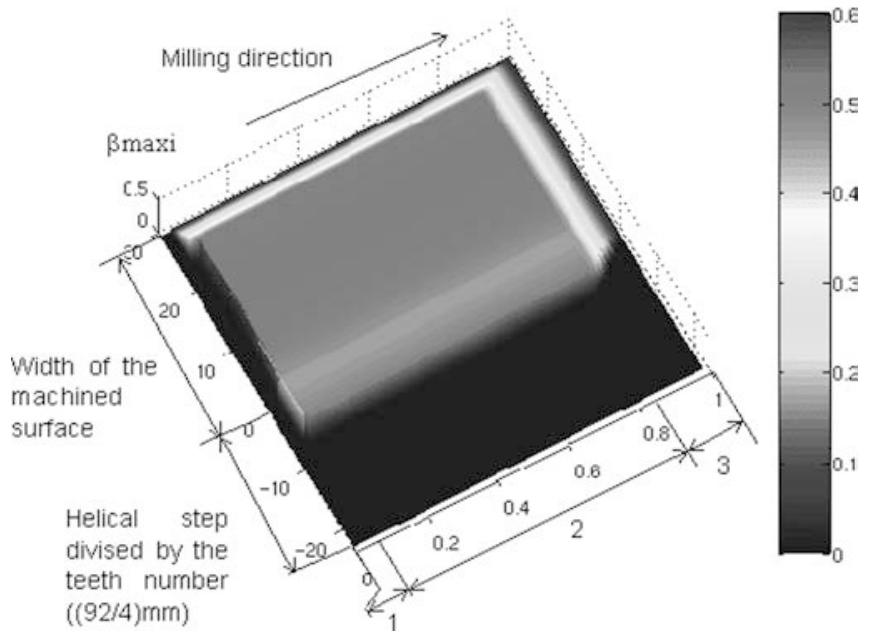

Fig. 20 The maximal engagement card

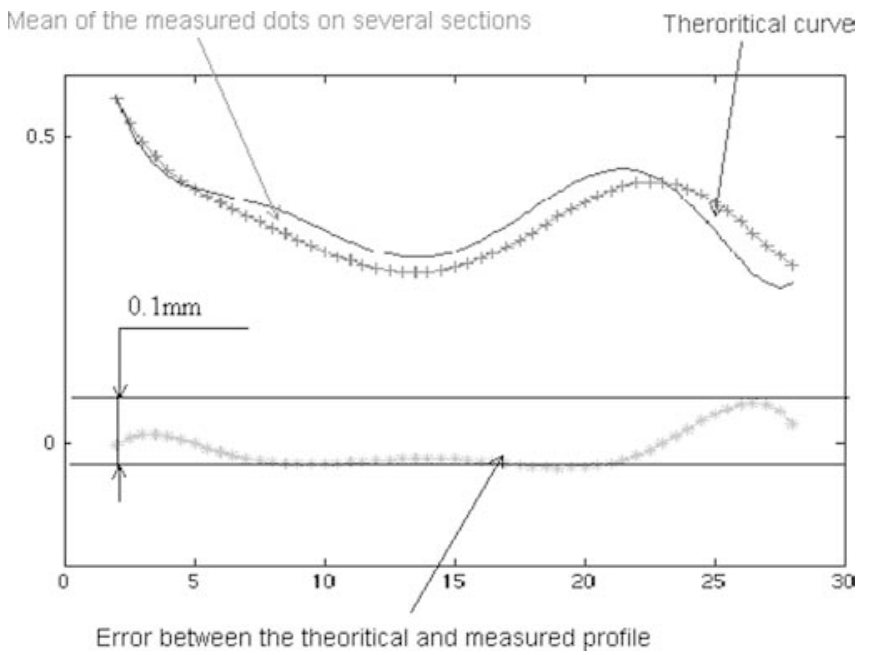

Fig. 21 The error profile between the cloud of simulated and measured dots

$90 \%$ of the height of a section. The method of prediction of defects proposed in this article is validated since it makes it possible to predict a peripheral machined defect at low speed. The error is such as:

$\left|\frac{\text { ecart }_{\text {calcule }}-e \text { ecart }_{\text {mesure }}}{e^{2} a r t_{\text {mesure }}}\right| \leqslant 5 \%$.

\section{Conclusions-prospects}

The method of prediction of peripheral milling defects proposed in this article is based on the estimation of the real tool engagement conditions. Several milling tests on different forms were carried out and made it possible to validate this method. The results obtained are satisfactory since we showed our capacity to predict the machined surface defects with a margin of $5 \%$. The method 
rests on the precise analysis of the tool generating points kinematics. Based on geometrical intersections calculations, this method is perfectly integrateable in a CAD environment. The workpiece material engagement card concept is significant. These cards represent a help to the generation of machined tool paths. They are useful to visualise the transition zones during which the tool engagement is variable. Our research tasks now tend to exploit the concept of an engagement card within the framework of the machined tool paths generation by respecting a constant tool engagement in the workpiece material. Another objective is the direct compensation of the defects estimated by the model previously described, the objective being to machine a part by respecting the functional constraints which were initially defined.

\section{References}

1. Smith S, Tlusty J (1991) An overview of modeling and simulation of the milling process. J Engin Indust 113:169-175

2. Smith S, Tlusty J (1993) Efficient simulation programs for chatter in milling. Annal CIRP 42(1):463-466

3. Altintas Y, Budak E (1995) Analytical prediction of stability lobes in milling. Annal CIRP 44(1):357-362

4. Tian J, Hutton SG (2001) Chatter instability in milling systems with flexible rotating spindles - a new theoretical approach. J Manufact Sci Engin 123(1):1-9

5. Insperger T, Stephan G, Bayly PV (2003) Stability of up-milling and down-milling, part 1: alternative analytical methods. Int $\mathbf{J}$ Mach Tool Manufact 43(1):25-34

6. Davies MA, Pratt JR, Dutterer BR, Burns TJ (2000) The stability of low radial immersion milling. Annal CIRP 49(1):37-40

7. Larue A, Anselmetti B (2003) Deviation of a machined surface in flank milling. Int J Mach Tool Manufact 43(2):129-138

8. Rubio W (2001) Analyse du positionnement et aide au choix d'outils pour l'usinage de formes gauches. Rapport d'habilitation à diriger des recherches, Université Paul Sabatier, Toulouse, France (in French)

9. Tönshoff HK (2000) Optimal tool positioning for five-axis flank milling of arbitrary shaped surfaces. Prod Engin 7(1)
10. Affouard A (2001) Introduction de l'interpolation polynomiale dans le cadre de l'usinage 5 axes par le flanc. Mémoire de DEA de production automatisée LURPA ENS Cachan, 2001 (in French)

11. Lartigue C, Duc E, Affouard A (2003) Tool path deformation in 5-axis flank milling using envelope surface. Comp-Aid Des 35(4):375-382

12. Kline WA, DeVor RE, Lindberg JR (1982) The prediction of cutting forces in end milling with application to cornering cuts. Int J Mach Tools Manufact 22(1):7-22

13. Seo TI (1998) Intégration des déformations outil en génération de trajectoires d'usinage. Dissertation, Ecole Centrale de Nantes (in French)

14. Altintas Y, Spence A (1991) End milling force algorithms for CAD systems. Annal CIRP 40(1):31-34

15. Ikua BW, Tanaka H, Obata F, Sakamoto S (2001) Prediction of cutting forces and machining error in ball end milling of curved surfaces - 1: theoretical analysis. Prec Engin J Int Soc P Engin Nanotech 25:266-273

16. Larue A, Anselmetti B, Soulier B (2001) Influence des déformations des fraises sur la qualité des surfaces usinées. In: 7ème colloque PRIMECA sur la conception intégrée La Plagne (France), Avril 2001 (in French)

17. Larue A, Anselmetti B (2002) Contribution to the tool paths generation in cam system. In: Proceedings of the 4th International Conference on Integrated Design and Manufacturing in Mechanical Engineering, Clermont, Ferrand, France, 14-16 May 2002

18. Software NCSIMUL, SPRING Technologies Society,http:/ www.ncsimul.com/default.asp?/index0.asp

19. Software VERICUT, CGTECH Society,http://www.cgtech.$\mathrm{com} /$

20. Software DELMIA, Dassault Systèmes Society,http:// www.delmia.com

21. Meng Lim E, Feng HY, Menq CH, Lin ZH (1995) The prediction of dimensional error for sculptured surface productions using the ball end milling process. Part 2: surface generation model and experimental verification. Int J Mach Tool Manufact 35(8):1171-1185

22. Sim S, Yang M (1993) The prediction of the cutting force in Ball end milling with a flexible cutter. Int $\mathbf{J}$ Mach Tool Manufact 33(2):267-284

23. Cho H, Yang M (1993) Precision pocketting in the ball end milling process. Int J Mach Tool Manufact 27(4):333-338

24. Sutherland JW, DeVor RE (1986) An improved method for cutting force and surface error prediction in flexible end milling systems. Trans ASME J Engin Indust 108:269-279 